\title{
Pelvic Bone
}

National Cancer Institute

\section{Source}

National Cancer Institute. Pelvic Bone. NCI Thesaurus. Code C33287.

The caudal portion of the trunk, bounded anteriorly and laterally by the two hip bones incorporating the socket portion of the hip joint for each leg. Posteriorly it is bounded by the sacrum and coccyx. 